Portland State University

PDXScholar

$5-22-2020$

\title{
The Representation of Rape and Sexual Assault Within News Media
}

Katherine E. Layman

Portland State University

Follow this and additional works at: https://pdxscholar.library.pdx.edu/honorstheses

Part of the Mass Communication Commons

Let us know how access to this document benefits you.

\section{Recommended Citation}

Layman, Katherine E., "The Representation of Rape and Sexual Assault Within News Media" (2020).

University Honors Theses. Paper 851.

https://doi.org/10.15760/honors.872

This Thesis is brought to you for free and open access. It has been accepted for inclusion in University Honors Theses by an authorized administrator of PDXScholar. Please contact us if we can make this document more accessible: pdxscholar@pdx.edu. 
The Representation of Rape and Sexual Assault Within News Media

\section{By}

Katherine E. Layman

An undergraduate honors thesis submitted in partial fulfillment of the

requirements for the degree of

Bachelor of Arts

in

University Honors

and

Communications

Thesis Adviser

Lee Shaker, PhD

Portland State University

2020 
Approximately every 73 seconds, someone is sexually assaulted in the United States (RAINN,2019). Rape and sexual assault are serious crimes and as such, they deserve to be accurately represented within the media. News media can reach a large number of people in a relatively short amount of time. The internet and social media dramatically expand that reach by creating platforms to share news articles all over the world. The public relies on journalists to be credible and honest in their reporting. However, the presence of rape myths, stereotypes, victim blaming and improper terminology within media coverage perpetuates the spread of misinformation about sexual violence.

The New York Times is a primary news source for millions of people globally, including those who make and enforce laws. Additionally, subscribers to The New York Times are not the only ones affected by the news it produces. As a well-known and reputable publication, The New York Times sets an example for other newspapers (Graber, 2018). Consequently, other news organizations may frame their own stories based on the information found in articles originally from New York Times (Graber, 2018). At a time when the integrity of the news industry is constantly being called into question, it is essential that leaders such as The New York Times resist sensationalism and remain objective in their reporting.

Through a content analysis of New York Times articles during three time periods over the past four decades, I examine how the framing of rape and sexual assault has changed from 1980 to 2020. I first selected my data set by searching the New York Times archives in ProQuest for articles about rape (or) sexual assault. I then narrowed the sample size by selecting random articles within three distinct time periods that mark significant societal changes regarding rape and sexual assault. The findings of this study show that news media coverage has changed in many ways that demonstrate a more comprehensive understanding of sexual violence. However, victim blaming 
attitudes within the New York Times had increased over time, despite an increase in public awareness and knowledge about rape and sexual assault.

To better understand why accurate representation about rape and sexual assault is so important, we first need to examine the different power structures involved, what rape myths and stereotypes are, and the influential role that mass media framing plays in shaping public discourse. Keywords: Rape, Sexual Assault, News Media, Framing, Rape Myths, Stereotypes and Victim Blaming

*Note: This thesis uses the term 'victim' in place of 'survivor' for two main reasons (1) the connotation of the word survivor implies that the victim's life was at risk- which is not the legal criteria for an assault to count as rape or sexual assault and (2) not all victims survive being attacked.

\section{News Media and Mass Communication}

The public depends on news organizations to give them vital information and to stay connected to the world at large (Lasswell, 1948). Three key functions of news media are: surveillance, interpretation and socialization (Lasswell, 1948; Graber, 2018)

Surveillance: News media keeps a close watch on events within society to bring awareness and provide facts to inform the public on a variety of local, national and international subjects (Lasswell, 1948). The news also provides a platform for experts to deliver a summary of details or guidance about subjects that the average person may have little knowledge about.

Interpretation: News organizations decide which pieces of news to produce. In doing so, journalists oftentimes report more than just factual data, they also analyze that information to provide context and meaning for the general public (Graber, 2018). 
Socialization: Social psychologists define socialization as the process by which people learn cultural and social norms, acceptable behavior and their role within society. News media plays a critical role in presenting and reinforcing ideas and social behaviors that prompt imitation (Prot, Anderson, Gentile, Warburton, Saleem, Groves \& Brown, 2015; Graber, 2018)

The public's reliance upon news media to perform these functions gives journalists tremendous power in influencing the audience's perceptions of the world around them (Lakoff, 2010). On a large scale, this power manifests as the news media's ability to help sway the passage of legislation by bringing awareness to an issue and by putting pressure on lawmakers to act (Lakoff, 2010). A positive example of this was the overwhelming national media coverage of the 1994 assault and murder of seven-year old Megan Kanka. This media attention sparked public outcry that helped to enact the federal policy informally known as "Megan's Law", which required the information on the law enforcement sex offender registry to become public (Levenson, J. \& D'Amora, D. 2007). News media framed the coverage of Megan Kanka's story to connect this singular horrific event to a larger societal problem that called for legislative action. However, there might not have been the same governmental intervention if the majority of journalists had presented her story from a different angle.

\section{Framing Theory: How Stories Are Told and Interpreted}

Framing is a fundamental aspect of communication and processing (Griffin, 2014). Our biases, needs and experiences shape the way that we communicate with others and relate to the world around us (Lakoff, 2010). In framing, the interpretation of a message depends on how the narrative is presented (Jennings, Thompson \& Finklea, 2012). Our minds instinctively filter out or link together information on a daily basis (Lakoff, 2010). The information that we consume is stored systemically and when certain frames are employed, all knowledge connected to a subject becomes 
activated. This brings the information to the forefront of our recall (Lakoff, 2010). These frames activate schemas or the system by which our mind categorizes and stores the information (Griffin, 2014). Since our brains rely on existing frame categories to file the information we receive, new input that contradicts the knowledge we already have is more difficult to process as the new data does not connect to the current framework (Lakoff, 2010).

\section{Semantic Framing: It's Not What You Say but How You Say It}

Semantic framing refers to the specific words or rhetoric [a journalist] choses to describe a story to influence or persuade people (Hallahan, 1999). In the context of media reporting on rape or sexual assault, the word accuser can invoke a less sympathetic reaction than the word victim (Katz, 2015). Vague or euphemistic terms such as, non-consensual sex sound less harsh than the term rape and can diminish the perceived severity of the crime (Bavelas \& Coates, 2001. Rape is defined by the Federal Department of Justice as, "Penetration, no matter how slight, of the vagina or anus with any body part or object, or oral penetration by a sex organ of another person, without the consent of the victim." (US Department of Justice, 2020). Therefore, under the state and federal definitions, sex without consent is rape and should be addressed as such. Passive Sentences such as 'she was sexually assaulted' or 'the rape occurred' can effectively remove the perpetrator from the conversation altogether (Henley, Miller, \& Beazley, 1995). Words that normally have a different definition can adhere to previously stored information about one meaning that does not necessarily fit the occurrence at hand. For example, verbs such as sex, caressed or fondled, are usually associated with pleasurable or consensual acts (Bavelas \& Coates, 2001). Consequently, when journalists use these verbs to describe a rape or sexual assault it can lessen the connection to violence or abuse (Bavelas \& Coates, 2001). 
News media convey stories in episodic or thematic frames. An episodic frame focuses on an isolated incident where a thematic frame places the incident within a broader context (Iyengar, 1990). These frames can influence the public's perception of who is at fault and what should be done about problems in terms of individual and societal responsibility (Iyengar, 1990). Episodic frames usually generate more sympathy from audiences due to the concentration on individual stories or events (Gross, 2008). In contrast, thematic frames tend to offer more statistical data which can appear more clinical rather than emotional (Gross, 2008). The thematic framing of sexual violence can address a wide range of problems and solutions that can affect society as a whole. However, episodic framing of rape and sexual assault can decrease the perception connection to a larger systemic problem (Brossoi, Roberto \& Barrow, 2012).

\section{Sexual Violence is Systemic and Cultural}

Systemic or institutionalized sexism is the stereotyping, prejudice and discrimination against women and girls on the basis of sex, that institutionally benefits men (Capodilupo, 2019). While gender-based discrimination can individually affect anyone, it differs from systemic sexism when there is no institutional oppression involved. Institutional oppression refers to the discriminatory practices of societal institutions such as governmental agencies and policies (laws, military, justice system and law enforcement), corporations (workplaces), financial institutions and public institutions such as schools and healthcare organizations (Capodilupo, 2019). Women as a whole have never had more rights, power of control than men. When an entire societal structure is designed to reinforce the idea that women are second-class citizens it creates a communal disregard for the exploitation of women. This collective consciousness is otherwise known as rape culture.

Rape culture is the term for a shared belief system amongst society that normalizes and justifies the sexual abuse and violence against women and girls (Herman, 1994). Rape culture 
influences the way that society as a whole talk about rape and sexual assault (Herman, 1994). Sexism and rape culture are maintained by the objectification and sexualization of women's and girl's bodies, use of misogynistic language, victim blaming and violence against women as a form of entertainment in film and music (Herman,1994). Over time, societal norms, attitudes, definitions and public policies about rape and sexual assault have changed to display a greater comprehension of these crimes. For example, the rape of a spouse (marital rape) was not even considered a crime in all 50 states until 1993 (National Center for Victims of Crime, 2004). Even though a majority of people personally find discrimination or violence against women to be abhorrent, they may still unintentionally perpetuate rape culture. Resulting from how commonplace rape culture practices and misconceptions are, that most people are unaware of them (Burt, 1980). Through historical social context, sexism has become ingrained within our culture (Burt, 1980). As a result, the existing frames many people may have stored about topics such as rape or sexual assault could stem from misinformation seen through the lens of this oppressive framework.

The US Department of Justice (DOJ) reports that rape and sexual assault are the most under reported and under prosecuted crimes. Yet, one in six boys and one in four girls will be victims of sexual abuse before they are 18 years old (Finkelhor, Shattuck,Turner \& Hamby,1990). A 2010 study conducted by the Centers for Disease Control and Prevention (CDC), National Center for Injury Prevention and Control (NCIPC) found that one in five women, one in seventy-one men will be raped at some point in their lives. The Office for Victims of Crime (OVC) reports that one out of two transgender individuals will be sexually assaulted during their lifetime. Meaning that, statistically, a large portion of media consumers are or will be victims of sexual violence in their lifetime. The Canadian Resource Center for Victims of Crimes (2020) states, "Media coverage can 
re-victimize victims, especially if overly sensational or inaccurate. It can reinforce misconceptions and myths about crime victims."

\section{Rape Myths, Stereotypes and Victim Blaming}

Rape Myths are "prejudicial, stereotyped or false beliefs about rape, rape victims, and rapists" that create a "climate hostile to rape victims" (Burt, 1980, p. 217). Myths and stereotypes include ideas such as: rape is about sexual arousal, all rapists are male, men cannot be raped, prostitutes cannot be sexually assaulted, or that the victim was careless in preventing the assault.

The main outcome of rape myths is the shift in blame from the perpetrator and onto the victim (Suarez \& Gadalla, 2010). Believing that a woman was asking to be raped or should have expected to be attacked because of her sexual history, alcohol consumption, actions, or because of how she was dressed are all examples of rape myths that perpetuate victim blaming beliefs. One rationale responsible for victim blaming is that people want to believe in a fair and just world where victimization is predictable and therefore avoidable (Lerner, 1980). This just-world belief reinforces the idea that what goes around, comes around and bad things happen to bad people. This may neutralize the fear of random crime. However, this belief reinforces the notion that the victim is in some way deserving of the assault (Lerner, 1980).

Acceptance of rape myths can have serious consequences within the criminal justice system as well. Perpetrators of sexual violence are the least likely to be incarcerated compared to all other types of criminals (RAINN, 2019). When journalists repeatedly frame perpetrators as monstrous or somehow distinguishable from the average person it can give the false impression that perpetrators are easy to spot and can make a jury skeptical when the person accused of rape or sexual assault does not fit this stereotype (O’Hara, 2012). Out of every 1000 rapes only 9 will ever be referred to a prosecutor and only 5 rapists will be convicted (RAINN, 2017). Rape myths can 
also impact how likely jurors are to believe victims and can affect their decision-making process at trial (Dinos, Burrowes, Hammond \& Cunliffe, 2015). Especially when the person who was assaulted does not seem like the ideal victim (Christie, N. 1986). The myth of the ideal victim is the misconception that the only victims deserving of empathy or support are pure, defenseless or virginal while victims who do not fit this dichotomy may have contributed to their own victimization (Howard, 1984; Christie, 1986; DiBennardo, 2018).

Sexual violence is a complex matter with a wide range of victims, perpetrators and circumstances. Yet, if the media focuses too intently on uncommon rape cases, it gives a distorted sense of how frequently these types of rapes occur and who is at risk (DiBennardo, 2018; Graber, 1977). This can also divert the conversation away from sexual assaults that do not resemble the ones represented within media coverage. For example, the majority of rapes (8 out of 10) are committed by an assailant who is known to the victim (RAINN, 2019) but if the news mainly covers rapes that are committed by strangers it can give the impression that stranger rape is more common than acquaintance rape-which is inaccurate.

\section{Methodology}

To conduct this content analysis, I identified relevant articles in The New York Times through the ProQuest database. I gathered a broad initial sample by searching with the keywords rape (or) sexual assault to find articles that contained either of these words. That search returned 72,486 results. I refined the search to only contain newspaper articles and that search yielded 36,023 articles containing the keywords. I then narrowed the search further by using the filter "sex crimes" which gave me a total of 8,232 articles. I then broke the search into 3 distinct time periods- 19801984 (total of 375 articles); 1993-1997 (total of 122 articles); 2016-2020 (total of 738 articles). I 
coded a total 150 articles, separated into 50 articles taken from each time period and randomized by using an integer set generator from Random.org. I also chose to exclude Op-eds since these are not done by the newspaper and it is stated that the views therein do not necessarily reflect the views of the New York Times. It is also important to note that due to the nature of my thesis as an independent paper, time constraints and conducting research during a global pandemic, I did not have a second coder.

The importance of the specific time periods is that they each coincide with a noticeable cultural shift in society regarding sexual violence. The first sample will be taken from between 1980 to 1984 to get a sense of the coverage in this time and provide a baseline to work from and to include the federal passage of the Sexual Assault Act (1984). The second data set will be taken from the timeframe of 1993 to 1997 due to the significant legislative changes regarding rape and sexual assault that were made during this time such as, Megan's Law (1994), Marital Rape Laws are present is all states (1993) and the Violence Against Women Act (1994). The final set will be taken from 2016 to present to encompass the viral expansion of the 2006 \#MeToo movement (2017) and \#WhyIDidntReport (2018), the expiration of the Violence Against Women Act (2018), the Kavanaugh hearing (2018) as well as Harvey Weinstein's and Jeffery Epstein's arrests (2017 and 2019 respectively). Another function of this last data set is to provide the most recent conversations about rape and sexual assault within The New York Times.

The coding method are broken down into 4 main categories with subcategories in each:

\section{(1) Presence of rape myths and/or stereotypes within an article.}

If the article contains references about:

- the victims clothing

- the victim's behavior before the assault (described as atypical, risky, flirty or provocative) 
- alcohol or drug consumption of victim

- "Atypical" perpetrator- anyone who does not fit the stereotypical male, stranger with a weapon

- $\quad$ stranger vs acquaintance rapes

- $\quad$ use of a weapon (only $11 \%$ of perpetrators use a weapon)

(2) Who is quoted first within the article:

- Law enforcement

- Advocates

- Experts

- Family/friends/neighbors

- Victims
- Witnesses

- Lawyers/Prosecutors

- Judges

- Defendants

\section{(3) Whether the article is framed as episodic, thematic or both}

Episodic- Focused on one incident- or multiple assaults done by the same person(s) with no reference to larger systemic connection

Thematic- Rape or sexual assault statistics, prevention and/or connections to rape culture or sexism or societal institutions.

\section{(4) Semantic Frames:}

Use of the word accuser in place of the word victim

The presence of consensual sexual language in place of violent terminology

- fondled, caressed, kissed, sex, performed, oral sex, engaged in

Euphemistic language 
- nonconsensual sex

- underage woman- there is no such thing, a female who is underage is not a woman

- abusive relationship- people are abusive, not relationships

- underage prostitute/sex worker-underage means a child/minor and a child/minor cannot legally consent to sex

The use of passive voice to describe the assault

- She was sexually assaulted

- $\quad$ The rape occurred /The rape happened at...

\section{Results}

Rape Myths and Stereotypes

\begin{tabular}{|l|r|r|r|}
\hline & $1980-84$ & $1993-97$ & $2016-20$ \\
\hline Weapon & 25 & 14 & 2 \\
\hline Stranger & 25 & 17 & 10 \\
\hline Multiple perps & 7 & 5 & 5 \\
\hline Victim drinking & 0 & 4 & 8 \\
\hline Vic. blaming & 0 & 6 & 11 \\
\hline "atypical" perp & 0 & 3 & 8 \\
\hline
\end{tabular}

Who Is Quoted First In The Article

\begin{tabular}{|l|r|r|r|r|}
\hline & $1980-84$ & & $1993-97$ & $2016-20$ \\
\hline Police & 11 & 17 & 3 \\
\hline Lawyers & 4 & 6 & 14 \\
\hline Judges & 1 & 1 & 4 \\
\hline Victim & 3 & 1 & 6 \\
\hline Advocate & 3 & 2 & 3 \\
\hline Family/friends & 0 & 3 & 3 \\
\hline Experts & 0 & 2 & 0 & 5 \\
\hline
\end{tabular}




\begin{tabular}{|l|r|r|r|}
\hline Community member & 3 & 5 & 3 \\
\hline Defendant & 1 & 2 & 3 \\
\hline Witness & 1 & 1 & 0 \\
\hline Government official & & & 5 \\
\hline
\end{tabular}

Episodic and Thematic Frames

\begin{tabular}{|l|r|r|rr|}
\hline & $1980-84$ & $1993-97$ & $2016-20$ & \\
\hline Episodic & 44 & 44 & 19 \\
\hline Thematic & 1 & 1 & 8 \\
\hline both E/T & 6 & 6 & 23 \\
\hline
\end{tabular}

Semantic Framing

\begin{tabular}{|l|r|r|r|r|}
\hline & $1980-84$ & $1993-97$ & $2016-20$ \\
\hline Passive voice & 9 & 7 & 4 \\
\hline Accuser & 0 & 2 & 10 \\
\hline & & & & 5 \\
\hline Consensual sexual lang. & 2 & 10 & 1 \\
\hline Euphemisms & 1 & 0 & \\
\hline
\end{tabular}

The Number of Articles That Mentioned a Victim's Gender

\begin{tabular}{|l|r|}
\hline Female Victim & 148 \\
\hline Male victim & 2 \\
\hline TGQN & 0 \\
\hline
\end{tabular}

* TGQN is an acronym for Transgender, Gender Queer and Gender-Nonconforming individuals

The Number of Articles That Mentioned a Perpetrator's Gender

\begin{tabular}{|l|r|}
\hline Female & 1 \\
\hline Male & 150 \\
\hline TGQN & 0 \\
\hline
\end{tabular}

* All 150 articles contained stories of male perpetrators and one article included two stories, where one was about a female perpetrator. 


\section{(1) Presence of rape myths and/or stereotypes}

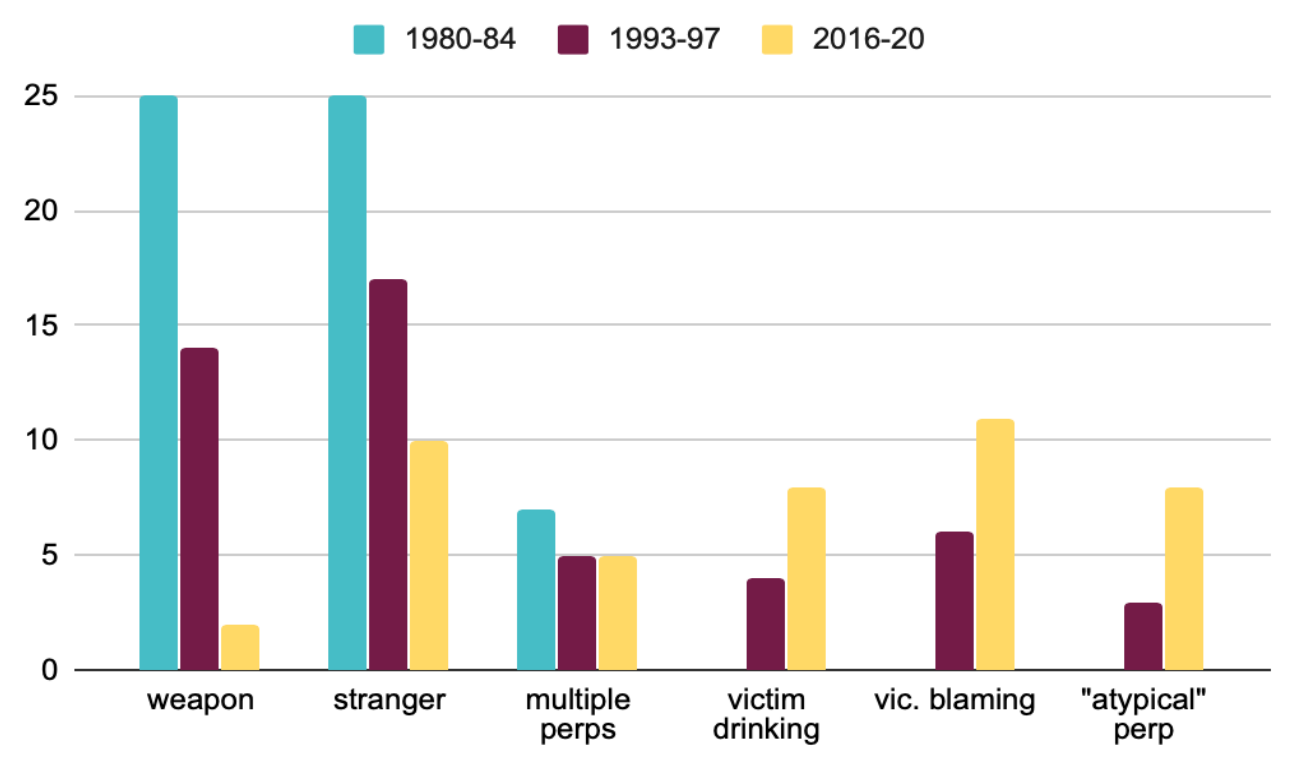

In total, 78\% of articles were about stranger rapes. However, rapes and sexual assaults perpetrated by a stranger only constitute $19.5 \%$ of actual rape cases and when the victim is a minor, the percentage of rapes committed by a stranger decrease to only 7\% (RAINN, 2019). Overall, $61.5 \%$ of articles mentioned the use of a weapon by the perpetrator. This stands in stark contrast to the reality of the majority of rape and sexual assaults, where a weapon is present in only $11 \%$ of attacks (RAINN, 2019). Out of 150 articles, $25.5 \%$ involved rape cases where there were multiple assailants, yet the real percentage of rapes committed by 2 or more people is less than 6\% (RAINN, 2019). The over representation of these types of assaults gives the impression that stranger rape and assaults that involve a weapon or multiple perpetrators occur more frequently than they actually do. Disproportionate media coverage of uncommon sexual assaults reinforces rape myths that narrowly define what rape is and who perpetrators are.

Consequently, many victims are reluctant to call what was done to them 'rape' because their experience does not resemble the stereotypical rape script of a stranger who jumps out from 
behind bushes or in an alley wielding a gun or a knife. A rape script is an individual's idea or belief of what normally happens during a rape (Peterson \& Muehlenhard, 2004). Dr. Charlene L. Muehlenhard, a professor of psychology at the University of Kansas and Dr. Zoe Peterson, the director and research scientist at the Kinsey Institute Sexual Assault Research Initiative concluded that stereotypical rape scripts and rape myths hold the belief that, "Rape occurs between strangers, involves weapons and extreme force, requires substantial victim resistance, and leaves the victim bruised and injured." (Peterson \& Muehlenhard, 2004, p. 131) However, these myths and rape scripts do not accurately reflect the legal definitions of rape or sexual assault or actual statistics.

In 50\% of articles from 1980-84 attacks were committed by strangers and a weapon was used in the assaults. That number drops in the second data set (1993-97) where 34\% of articles were about stranger rape and $28 \%$ mentioned the use of a weapon. The numbers decreased dramatically in the final data set (2016-20) to $20 \%$ of articles about stranger rapes and only $4 \%$ included a weapon. This drop in coverage of infrequent assaults may be due to the increased research, education and awareness about acquaintance rapes and how the legal definitions of rape and sexual assault have expanded overtime to include coercion, incapacitation by drugs or alcohol and place an emphasis on the victim's lack of consent (US Department of Justice, 2012).

Victim drinking and victim blaming was not found in any articles from the first data set in 1980-84. This increased in the second data set (1993-97) and was the most prevalent within the last set (2016-20). As previously stated, education and awareness surrounding sexual violence has greatly increased over the past four decades yet victim blaming, when present, would seem to suggest otherwise. Sexual violence no longer lives in the shadows of society's consciousness. The abundance of educational campaigns about rape and sexual assault have brought recognition to this pressing issue. Consequently, awareness and statistical data that showcase the overwhelming 
occurrence of sexual violence can also breed a heightened sense of fear over victimization (Warr, 1985; Callanan, 2012) which can result in increased victim blaming attitudes (Lerner, 1980). This may explain the $80 \%$ increase in victim blaming within the final and most recent data set. In other words, safety is a primal instinct which means we all want to feel safe and in control, yet sexual violence can frighten us and make us feel vulnerable.

Oftentimes, victim blaming is a subconscious attempt to placate our own fears by distancing ourselves from the victim as much as possible (Lerner, 1980). If we convince ourselves that certain behaviors or actions of the victim contributed to their victimization, we gain a false sense of control by believing that we can avoid becoming a victim if we simply avoid the identified behaviors. Other times, victim blaming is simply a product of how ingrained rape culture and misogyny is within our society (Burt, 1980).

Perhaps what was most disturbing about victim blaming attitudes was who harbored them. Judges expressed the highest amount of rape myth acceptance and direct victim blaming. This is extremely problematic because judges have the power to dismiss cases, allow or exclude evidence, decide sentencing and determine the guilt or innocence of a defendant in the absence of a jury. A victim depends on judges to be impartial and to follow facts. However, when the very person who has the highest power in the courtroom holds biased beliefs about victims or perpetrators- it can have devastating consequences on victims and society.

One common misconception amongst the judges that showed victim blaming attitudes and rape myth acceptance was the belief that men/boys who come from good educated families or have bright academic futures do not fit the mold of a rapist. This myth of the stereotypical perpetrator reinforces the illusion that all rapists are easily identifiable- when in reality, perpetrators are present in all races, genders, education levels and social classes. For the sake of coding this study 
the term, "atypical perpetrator", encompasses anyone that does not fit the stereotypical idea of what a rapist looks and acts like. In the data sets from 1993-97 \& 2016-20 articles included atypical perpetrators ranging from celebrities, wealthy businessmen, high academic or athletic status, government officials, police officers and even one woman. This increase in news coverage with a wider variety of perpetrators may also be due to the increase in social awareness around sexual violence. News reports about rapes and sexual assaults that go against stereotypes can help to expand the public's understanding of sexual violence.

\section{(2)Who is quoted first within the article}

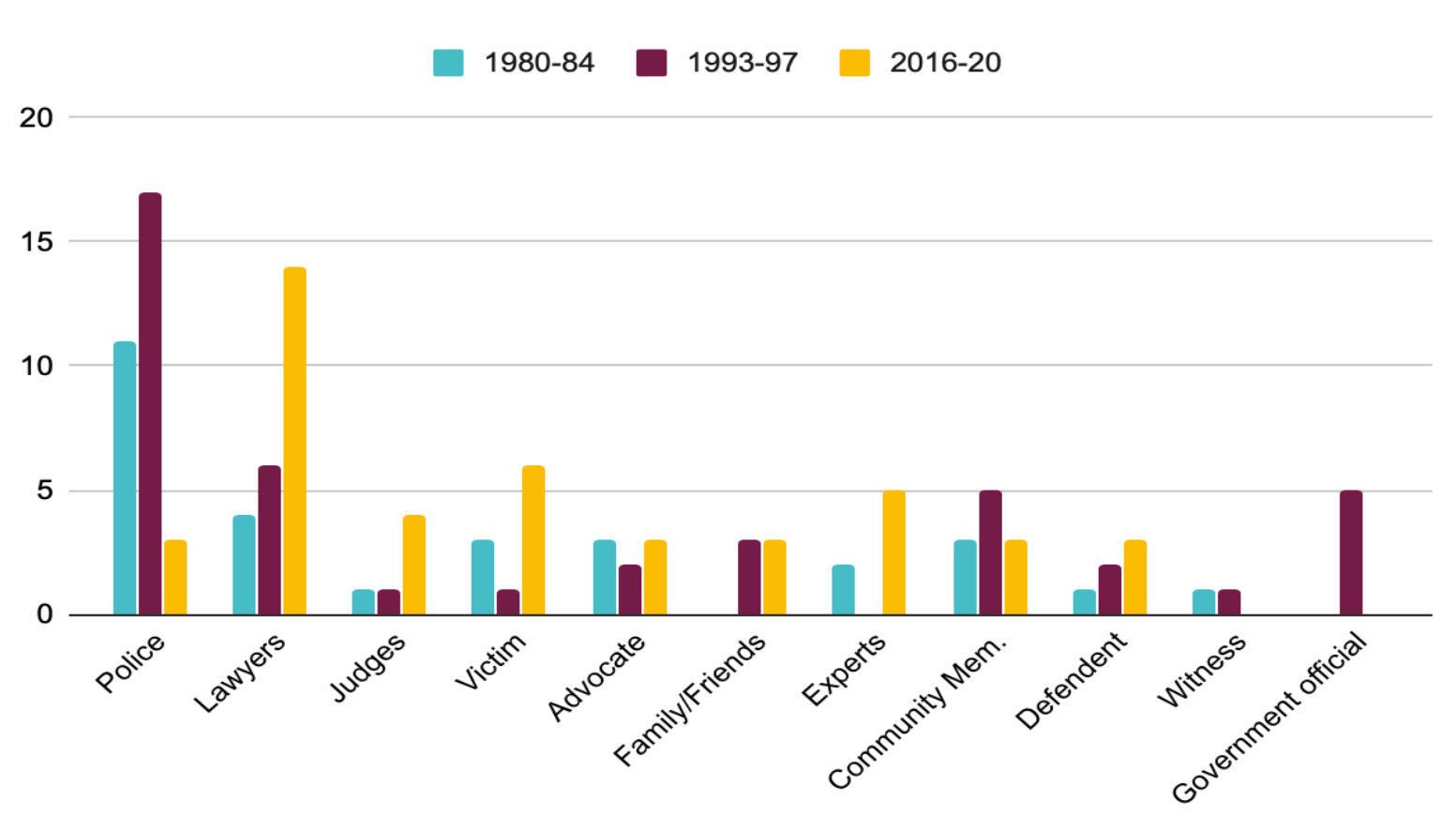

Who is quoted first within the article sets the tone for the conversation as a whole. In the data sets from 1980-84 and 1993-97, the police and spokespeople for the police departments were overwhelmingly quoted first in articles. However, in the final data set (2016-20) lawyers were the highest to be quoted first. Another difference in this data set is the increase in judges, victims, defendants and experts as the first ones quoted. It is interesting to note that in 2 out of the 3 articles 
in 2016-20 that quoted the defendant first, the accused was President Donald J. Trump. Experts are defined as psychologists, professors, therapists and academic researchers whose area of expertise is in sexual violence or the law.

\section{(3) Thematic and Episodic Frames}

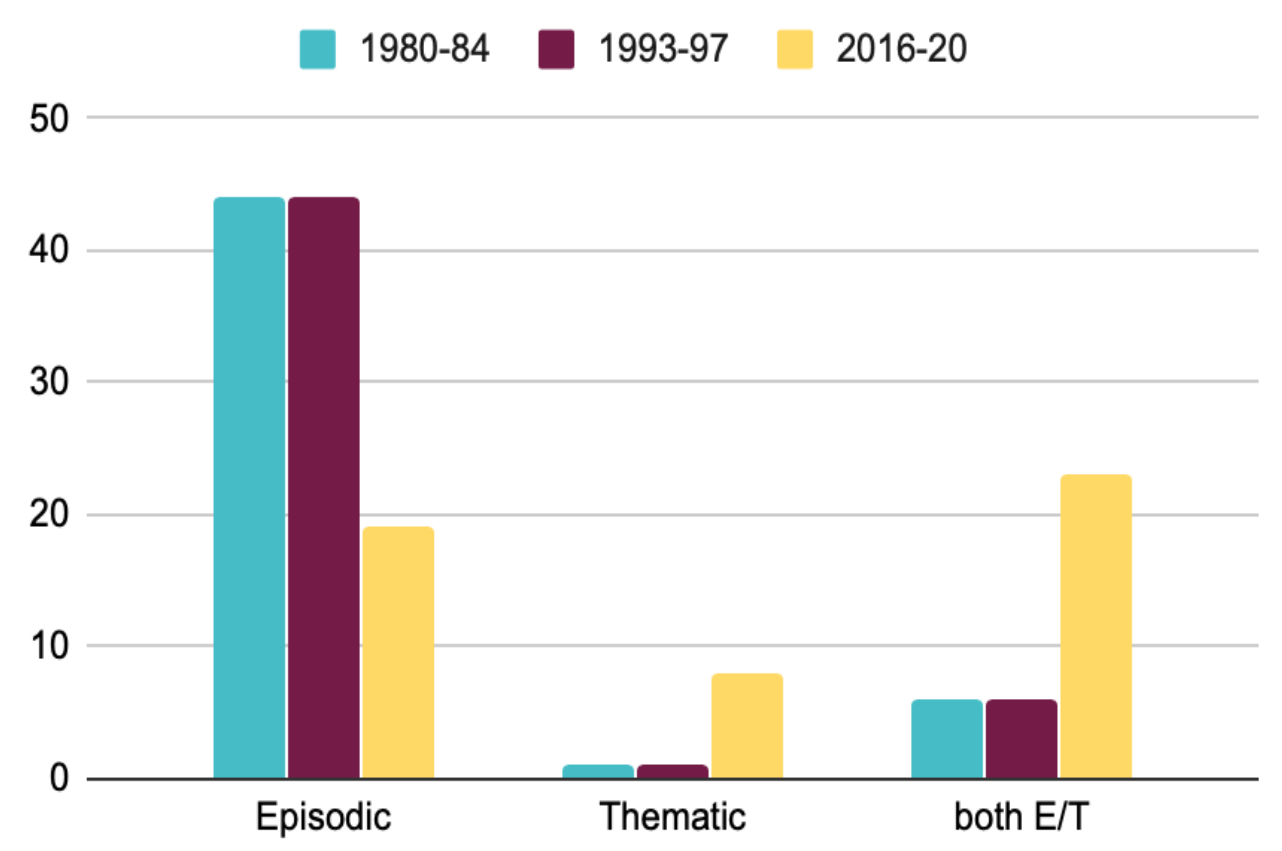

In total, 107 articles were presented from a purely episodic perspective. Meaning that, the majority of reports characterized the rape or sexual assault as a singular event with no connection to the larger societal framework of sexual violence. Purely thematic articles contained proposed policies legislation or general statistics but left out more personalized stories of victims. Articles that contained both thematic and episodic frames focused on singular acts of sexual violence and then tied in statistics and concepts such a rape culture, public policy or societal perceptions.

In the first two data sets from 1980-84/1993-97, the number of episodic, thematic and a mixture of both frames were identical- 44 (episodic) 1 (thematic) and 6 (both T/E). However, in the third and most recent data set from 2016-20, there is a significant change- 19 (episodic), 8 
(thematic) and 23 (both T/E). From this data we can see that a greater link is made between an incident of rape or sexual assault and where that event fits in the larger scale of sexual violence. This could be representative of a changing perception of what contributes to rape and sexual assault in our society. Through increased education and awareness, we now have a better understanding of rape culture and how sexual violence is linked to certain system failures that make it easier for predators to escape punishment and harder for victims to receive support (Shen, 2011; Thacker, 2017).

A mixture of episodic and thematic frames can report the victim's personal story and also place the incident into social context which allows us to explore the societal changes that can be made to combat sexual violence such as; legislation, community response, criminal justice system practices and trauma informed care training (Cox, Lang, Townsend, \& Campbell, 2010; Allison \& Wrightsman,1993). However, when an assault is looked at from a purely episodic standpoint it reduces the problem to a series of disconnected and seemingly random incidents. A detached view of the problem can promote victim blaming attitudes since the focus is more on what the individual victim could have done to prevent the attack instead of on what we can do as a community. 


\section{(4) Semantic Framing}

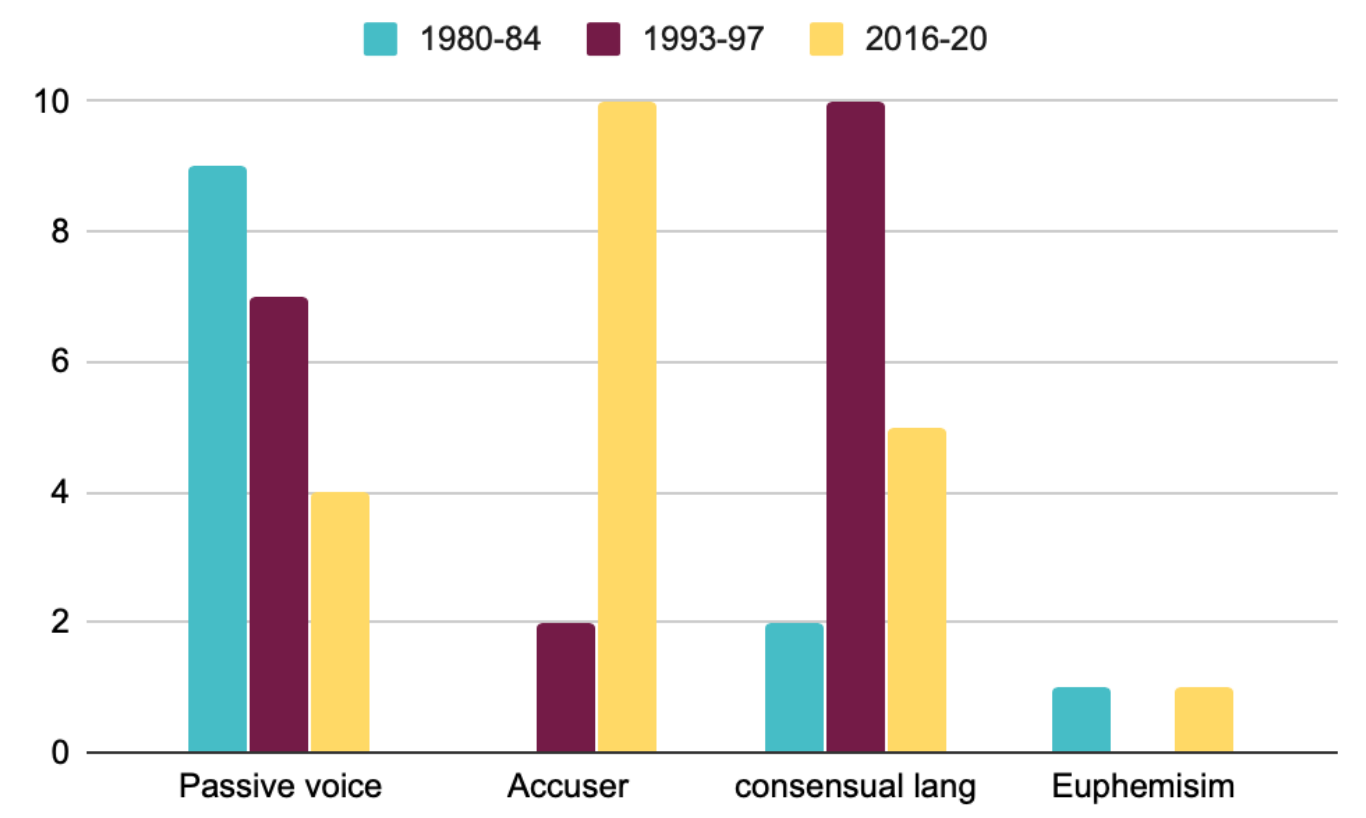

As shown in the chart, the use of passive voice when referring to a rape or sexual assault declined consistently over the time periods. Consensual sexual language was used most frequently in the 1993-97 and included "fondled", "performed", "sex acts" "had sex" and "sexual relations". The phrases "had sex" and "sexual relations" were mainly used in articles that involved adult males raping female children and teens who, being underage, could not legally consent to sex. Consensual sexual language declined by $50 \%$ in the subsequent data set (201620). Euphemistic language was peasant in only two articles in total.

The use of the word accuser to replace the word victim had increased over time. Accuser was not used in any articles during the 1980-84-time frame; the second time period used the word accuser in only two articles and the most recent time frame, 2016-20, is where it is used the most. However, the significance is not the amount of times the word accuser is used but when it is used. Put differently, the only times the word accuser was used to replace the word victim had more to do with who was being accused of rape or sexual assault than who the victim was. In every article 
that used the word accuser, the alleged perpetrator of sexual assault did not fit the stereotypical rapist as the deranged weapon wielding stranger and all were men of privilege through either or a combination of extreme wealth, athletic achievement, celebrity or career status.

The word victim implies that a person had something harmful done to them. However, when the word accuser replaces the word victim- the person who was hurt now becomes the one who is doing something to another. The accused then becomes the victim of an accusation (Katz, 2015). When journalists use the word accuser instead of victim or alleged victim it can shift the focus off of the accused and onto the victim's actions and credibility (Katz, 2015). The victims become the one whose motives are placed under scrutiny rather than the alleged actions of the accused (Katz, 2015).

\section{Victims and Perpetrators by Gender}

While gender was not a specific focus of my study, it was a theme that became quite obvious once I started examining articles. One significant issue was the lack of representation for men, transgender, genderqueer and gender-nonconforming victims (TGQN). While it is true that women and girls make up a majority of rape and sexual assault victims, they are not the only ones who are victimized. Within all 150 articles, there were only 2 male victims mentioned and both were children. Members of the TGQN community were not listed as victims or perpetrators in any articles. Disproportionate coverage of the stereotypical dichotomy of male perpetrator and female victim leave other victims' experiences out of the larger conversation. Even though the majority of perpetrators are men, women and nonbinary folks perpetrate crimes of sexual violence as well. However, out of 150 articles, all 150 listed male perpetrators and only 1 article also included a story about a female perpetrator. 


\section{Conclusion}

In some ways, news coverage in The New York Times has changed over the past four decades to reflect a better understanding of rape and sexual assault past many stereotypical rape myths and episodic framing. Rape and sexual assault education and awareness campaigns are more prevalent today than they were in the 1980 s, leading to a significant societal shift in perspective about the different aspects that play a role in sexual violence (National Sexual Assault Resource

Center, 2020; McMahon, S. Baker, K., 2011). While the perpetrator is responsible for their actions, the behavior of an individual is not the only factor that allows widespread sexual violence to continue. Rape myth acceptance has infiltrated the very systems that are supposed to help victims.

Unfortunately, there has been an increase in victim blaming within The New York Times coverage since the 1980s. Why victim blaming statements have increased in The New York Times despite the expansion of sexual violence education and awareness would be an interesting area for further research. Furthermore, the lack of representation of certain victim groups stayed consistent throughout, which suggests that The New York Times has left many victims' voices unheard and proposes that more research on this subject is warranted.

The way that news organizations talk about sexual violence can either have positive or negative effects on a micro and macro scale. On a personal level, news media framing can influence how an individual think about rape and sexual assault (Conlin \& Davie, 2015).

In some instances, media framing can have more of an effect on a person's perspective than personal experience and even more so when a person's understanding about a topic is minimal (De Vreese, 2005). On a grander scale, media framing can also impact legislation, funding for support services, conviction and arrest rates and how society as a whole perceives and responds to sexual violence (Conlin \& Davie, 2015). 
This study shows that the framing of rape and sexual assault within The New York Times has made some significant changes since the 1980s that indicate greater insight into the complexities of sexual violence. However, this study also highlights the areas that could use improvement and suggestions for further research.

Words matter. How we talk about rape and sexual assault matters. It is important to observe the way that news organizations represent sex crimes, perpetrators and victims since the media can be crucial in shaping public beliefs about rape and sexual assault which can result in significant repercussions for victims and society as a whole (Levenson, J. \& D'Amora, D. 2007). 


\section{Work Cited}

Allison, J. A., \& Wrightsman, L. S. (1993). Rape: The misunderstood crime. Sage.

Bavelas, J. \& Coates, L. (2001). Is It Sex or Assault? Erotic Versus Violent Language in Sexual Assault Trial Judgments. Journal of Social Distress and the Homeless. 10. 29-40.

https://www.researchgate.net/publication/226195887_Is_It_Sex_or_Assault_Erotic_Versus_Viol ent_Language_in_Sexual_Assault_Trial_Judgments

Burt, M (1980) Cultural myths and supports for rape. Journal of Personality and Social Psychology 38(2): 217-230. https://search-proquestcom.proxy.lib.pdx.edu/docview/614292712/fulltextPDF/B7649343D8F04E77PQ/1?accountid=1 $\underline{3265}$

Brossoie, N., Roberto, K.A., Barrow, K.M. (2012) Making Sense of Intimate Partner Violence in Late Life: Comments From Online News Readers, The Gerontologist, Volume 52, Issue 6, Pages 792-801, https://doi.org/10.1093/geront/gns046

Callanan, V. (2012). Media Consumption, Perceptions of Crime Risk and Fear of Crime: Examining Race/Ethnic Differences. Sociological Perspectives, 55(1), 93-

115https://www.jstor.org/stable/10.1525/sop.2012.55.1.93?seq=2\#metadata_info_tab_contents

Capodilupo, C. (2017) Institutional sexism. In K. Nadal (Ed.), The SAGE encyclopedia of psychology and gender(pp. 941-942). Thousand Oaks,, CA: SAGE Publications, Inc https://sk.sagepub.com/reference/the-sage-encyclopedia-of-psychology-and-gender/i10276.xm

The Canadian Resource Center for Victims of Crimes https://crcvc.ca/publications/media-guide/victimsand-medial

Centers for Disease Control and Prevention \& National Center for Injury Prevention and Control (2010) National Intimate Partner and Sexual Violence Survey Summary Report https://www.cdc.gov/violenceprevention/pdf/nisvs_executive_summary-a.pdf

Christie N. (1986) The Ideal Victim. In: Fattah E.A. (eds) From Crime Policy to Victim Policy. Palgrave Macmillan, London https://link.springer.com/chapter/10.1007/978-1-34908305-3_2\#citeas

Coates, L., Bavelas, J. B., \& Gibson, J. (1994). Anomalous Language in Sexual Assault Trial Judgments. Discourse \& Society, 5(2), 189-206. https://doi.org/10.1177/0957926594005002003

Cox, P. J., Lang, K. S., Townsend, S. M., \& Campbell, R. (2010). The rape prevention and education (RPE) theory model of community change: Connecting individual and social change. Journal of Family Social Work, 13(4), 297-312. https://www.tandfonline.com/doi/abs/10.1080/10522158.2010.492494?casa_token=mocxZmt2o HcAAAAA:xUqKWwFCVcljwk1nCDouRBJwtkJzaGkx5_3EDmZgOtBHGyn5i88qwUG1J1TWasdEYyjx88nemc6mA 
Dinos, S., Burrowes, N., Hammond, K., \& Cunliffe, C. (2015). A systematic review of juries' assessment of rape victims: Do rape myths impact on juror decision-making? International Journal of Law, Crime and Justice, 43(1), 36-49. https://www-sciencedirectcom.proxy.lib.pdx.edu/science/article/pii/S1756061614000482

Encyclopedia Britannica- Institutionalized sexism (2019 https://www.britannica.com/topic/sexism

Federal Department of Justice- Rape Definition https://www.justice.gov/archives/opa/blog/updateddefinition-rape

Finkelhor, D., Shattuck, A., Turner, H., \& Hamby, S. (2014). The Lifetime Prevalence of Child Sexual Abuse and Sexual Assault Assessed in Late Adolescence. Journal of Adolescent Health, 55(3), 329-333.http://www.unh.edu/ccrc/pdf/9248.pdf

Graber, D., \& Dunaway, Johanna. (2018). Mass media and American politics (Tenth ed.). Thousand Oaks, California: CQ Press, An imprint of SAGE Publications.

Graber, D., \& Educational Resources Information Center. (1977). Crime News Coverage in Perspective. S.l. Distributed by ERIC Clearinghouse. https://files.eric.ed.gov/fulltext/ED151842.pdf

Griffin, E., Ledbetter, A., \& Sparks, G. (2014). A First Look at Communication Theory 9th edition. New York, NY: McGraw-Hill.

Gross, K. (2008). Framing Persuasive Appeals: Episodic and Thematic Framing, Emotional Response, and Policy Opinion. Political Psychology, 29(2), 169-192.

https://www.jstor.org/stable/20447111?seq=5\#metadata_info_tab_contents

Hallahan, K. (1999). Seven Models of Framing: Implications for Public Relations. Journal of Public Relations Research, 11(3), 205-242.

http://web.a.ebscohost.com.proxy.lib.pdx.edu/ehost/pdfviewer/pdfviewer?vid=1\&sid=7ccb1a84$\underline{8854-4 a 4 c-a 55 c-3383529 f b a 45 \% 40 s d c-v-s e s s m g r 01}$

Henley, N. M., Miller, M., \& Beazley, J. A. (1995). Syntax, Semantics, and Sexual Violence: Agency and the Passive Voice. Journal of Language and Social Psychology, 14(1-2), 60-

84. https://journals-sagepub-com.proxy.lib.pdx.edu/doi/pdf/10.1177/0261927X95141004

Herman, D. F. (1994) "The Rape Culture". Printed in Women: A Feminist Perspective. McGraw Hill. http://homepage.smc.edu/delpiccolo_guido/soc1/soc1readings/rape\%20culture final.pdf

Iyengar, S. (1990). Framing responsibility for political issues: The case of poverty. Political behavior, 12(1), 19-40. https://www.uvm.edu/ dguber/POLS234/articles/iyengar.pdf

Jennings, B. Thompson, S. Finklea B. W. (2012) Fundamentals of Media Effects: Second Edition. (n.p.):Waveland

Press https://www.google.com/books/edition/Fundamentals_of_Media_Effects/XcUQAAAAQB $\underline{\mathrm{AJ}}$ ?hl=en\&gbpv=0 
Katz, J. (2015). Let's stop calling Bill Cosby's victims 'accusers'. Women's E-News, 21. http://www.calcasa.org/wp-content/uploads/2015/08/4-15-Sexual-Assault-Preventions-as-aLeadership-Issue-Lets-Stop-Calling-Bill-Cosbys-Victims-Accusers.pdf

Kramer, K. M. (1994). Rule by myth: The social and legal dynamics governing alcohol-related acquaintance rapes. Stan. L. Rev., 47, 115.

Lakoff, G. (2010). Why it matters how we frame the environment, Environmental communication,4(1), 70-81, https://doi.org/10.1080/17524030903529749

Lasswell, H. D. (1948). The structure and function of communication in society. The communication of ideas, 37(1), 136-139. http://www.irfanerdogan.com/dergiweb2008/24/12.pdf

Lerner, M. (1980). The belief in a just world : A fundamental delusion(Perspectives in social psychology). New York: Plenum Press.

Levenson, J. \& D'Amora, D. (2007). Social Policies Designed to Prevent Sexual Violence: The Emperor's New Clothes? Criminal Justice Policy Review, 18(2), 168-199. https://journalssagepub-com.proxy.lib.pdx.edu/doi/pdf/10.1177/0887403406295309

McCombs,M. Shaw, D.L. (1974) A Progress Report On Agenda-Setting Research. Annual Meeting Of The Association for Education in Journalism https://files.eric.ed.gov/fulltext/ED097682.pdf

McCombs, M.F. Llamas, J.P. Lopez-Escobar, E. Rey, F. (1997). "Candidate images in Spanish elections: Second-level agenda-setting effects". Journalism \& Mass Communication Quarterly. 74 (4): 703-17. http://pdfs.semanticscholar.org/9de3/976c0f48ac5b9516d3ad85bca4bc52b6d1c9.pdf

McMahon, S. Baker, K. (2011). Changing Perceptions of Sexual Violence Over Time. National Online Resource Center on Violence Against Women. VAWnet.org. https://vawnet.org/sites/default/files/materials/files/2016-09/AR_ChangingPerceptions.pdf

National Center for Victims of Crime (2004) Spousal Rape Laws 20 Years Later http://www.ncdsv.org/images/NCVC_SpousalRapeLaws20YearsLater_2004.pdf

National Sexual Violence Resource Center (2020). History of Sexual Assault Awareness Month. NSVRC.org. https://www.nsvrc.org/saam/history

US Department of Justice, Office for Victims of Crime (2014). Responding to Transgender Victims of Sexual Assault. OVC.gov. https://www.ovc.gov/pubs/forge/sexual_numbers.html

O'Hara, S. (2012). Monsters, playboys, virgins and whores: Rape myths in the news media's coverage of sexual violence. Language and Literature, 21(3), 247-259. https://journals-sagepubcom.proxy.lib.pdx.edu/doi/full/10.1177/0963947012444217 
Prot, S., Anderson, C. A., Gentile, D. A., Warburton, W., Saleem, M., Groves, C. L., \& Brown, S. C. (2015). Media as agents of socialization. Handbook of socialization: Theory and research, 276300.

https://books.google.com/books?hl=en\&lr=\&id=vTRFBQAAQBAJ\&oi=fnd\&pg=PA276\&dq=s ocialization+mass+media\&ots=XUeMJjuV4U\&sig=dQDvKm7rKbr5hdovY3HD8JE$\underline{\mathrm{rHo} \# \mathrm{v}=\text { onepage } \& \mathrm{q}=\text { socialization } \% 20 \text { mass } \% 20 \text { media\& } \mathrm{f}=\text { false }}$

Shen, F. X. (2011). How we still fail rape victims: Reflecting on responsibility and legal reform. Colum. J. Gender \& L., 22, 1.

Suarez, E., \& Gadalla, T. (2010). Stop Blaming the Victim: A Meta-Analysis on Rape Myths. Journal of Interpersonal Violence, 25(11), 2010-2035. http://pdfs.semanticscholar.org/9685/21415c13224139d8f258bf621ff6d579cd43.pdf

Thacker, Lily K. (2017) "Rape Culture, Victim Blaming, and the Role of Media in the Criminal Justice System," Kentucky Journal of Undergraduate Scholarship: Vol. 1 : Iss. 1 , Article 8. https://encompass.eku.edu/kjus/vol1/iss1/8

Warr, M. (1985). Fear of Rape among Urban Women. Social Problems, 32(3), 238-250. https://www.jstor.org/stable/800684?seq=10\#metadata_info_tab_contents 